\title{
ИНСТРУМЕНТЫ И МЕТОДЫ СОЦИАЛЬНО-ЭТИЧНОЙ МАРКЕТИНГОВОЙ ДЕЯТЕЛЬНОСТИ И ИХ ВОЗМОЖНОСТИ ПРИМЕНЕНИЯ В СОСТАВЕ МАРКЕТИНГОВОЙ ФУНКЦИИ ВУЗА
}

\author{
(c) 2021 Максаев Артур Анатольевич \\ кандидат педагогических наук, доцент, Кафедра менеджмента и торгового дела \\ Краснодарский кооперативный институт (филиал) \\ АНОО ВО Центросоюза РФ «Российский университет кооперации», Россия, Краснодар \\ E-mailmaksaev@mail.ru
}

В научной статье рассматриваются возможности прикладного использования маркетинговых методов и инструментов в контексте постановки и реализации задач социально-этичной маркетинговой концепции вузов на региональных рынках. Раскрыты маркетинговые аспекты формирования, использования и модернизации локальной нормативно-правовой базы реализации корпоративной социальной ответственности (ЛНПБ КСО) образовательной организации, формализовано содержание социально-этического компонента стратегической маркетинговой деятельности вуза, охарактеризованы перспективы расширения круга субъектов организации маркетинговой деятельности вуза, необходимого для реализации социально-этичных приоритетов, исследованы социально-этичные особенности реализации комплекса маркетинга образовательного учреждения и персонал как ключевой внутренний маркетинговый партнер вуза в части маркетингового сопровождения процессов реализации КСО.

Ключевые слова: корпоративная социальная ответственность, социально-этичная маркетинговая концепция, стратегия и комплекс маркетинга вуза.

Основным нормативным документом, регламентирующим практику применения инструментария КСО в Российской Федерации является Национальный стандарт Российской Федерации ГОСТ Р ИСО 26000-2012 «Руководство по социальной ответственности» [9]. Прикладные проблемы применения корпоративной социальной ответственности в деятельности российских предприятий в настоящее время относятся к числу перспективных и интересных управленческих новаций, исследование которых осуществляется уже в течении значительного промежутка времени с использованием современной исследовательской методологии социально-этичного маркетинга (отметим и положительно оценим информационную ценность реализуемого Ассоциацией менеджеров России исследования проблем КСО, результатом которого является ежегодный Национальный доклад [4], а также исследование О.А.Третьяк, посвященное глубокому содержательному анализу ретроспективы реализации корпоративной социальной ответственности на основе «Доклада о социальных инвестициях в России - 2014: к со3данию ценности для бизнеса и общества» [10]).

Ключевыми аспектами управления корпоративной социальной ответственностью, рассмо- тренными и детализированными в национальном стандарте являются:

- особенности организации управления с использованием принципов КСО;

- учет и реализация базовых прав человека при реализации управленческих воздействий и взаимодействий;

- социальная ответственность в трудовых отношениях;

- ответственность в отношении окружающей среды;

- ответственность в отношении значимых социальных проблем и противодействие их разрастанию (коррупция, вовлечение в политические процессы, конкуренция, цепочка создания стоимости, права собственника);

- ответственность в отношении взаимоотношений с потребителями;

- ответственность за участие в деятельности местных сообществ и вклад в их развитие [9].

Прикладная реализация социально-этичной управленческой и маркетинговой методологии подразумевает сквозное и комплексное внедрение соответствующих подходов и инструментов в стратегическое, операционное и тактическое управление.

Ключевой категорией рассмотренного стан- 
дарта является не собственно стандартизированная норма, а скорее указание к некой деятельности, способной в длительной перспективе принести положительные эффекты, имеющие, в том числе в маркетинговое значение, для субъектов процессов реализации корпоративной социальной ответственности. Подчеркнем также наличие в тексте стандарта ссылок на наличие международных и отраслевых объединений, участвующих в процессах продвижения тематики, проблем и инструментов реализации $\mathrm{KCO}$, а также отсутствие в этом списке отраслевых объединений сферы образования, которое, на наш взгляд, имеет стратегическое значение в выработке и реализации социально-этичных стандартов, практик и инструментов в средне- и долгосрочной перспективе.

Особенности маркетингового сопровождения процессов разработки, внедрения, использования и модернизации локальной нормативно-правовой базы реализации КСО вуза представлены на рис. 1 .

На всех пяти этапах разработки и внедрения ЛНПБ КСО возможно применение специализированного маркетингового инструментария, способного существенно повысить эффектив-

\begin{tabular}{|c|c|c|}
\hline \multicolumn{3}{|c|}{ Локальная нормативно-правовая база реализации КСО вуза (ЛНПБ КСО) } \\
\hline $\begin{array}{l}\text { Этапы формирования, } \\
\text { использования и } \\
\text { модернизации }\end{array}$ & & Маркетинговое сопровождение \\
\hline $\begin{array}{l}\text { 1. Формирование } \\
\text { технического задания на } \\
\text { разработку с учетом } \\
\text { международных и } \\
\text { отечественных стандартов, } \\
\text { лучших отраслевых практик }\end{array}$ & & $\begin{array}{l}\text { 1.1. Специализированное маркетинговое исследование кабинетного формата, } \\
\text { обеспечивающее формирование релевантного массива вторичных данных и } \\
\text { экспертную оценку возможностей их использования в операционной / } \\
\text { маркетинговой стратегии вуза }\end{array}$ \\
\hline $\begin{array}{l}\text { 2. Разработка комплекта } \\
\text { документов локальной } \\
\text { нормативно-правовой базы } \\
\text { реализации КСО вуза }\end{array}$ & $\rightarrow$ & $\begin{array}{l}\text { 2.2. Экспертная оценка состава, структуры и прогноз эффективности ЛНПБ КСО вуза. } \\
\text { 2.3. Бенчмаркинг ЛНПБ КСО в сравнении с лучшими отраслевыми и межотраслевыми } \\
\text { практиками. 2.4. Прогноз маркетинговой эффективности прикладного внедрения } \\
\text { ЛНПБ КСО в кратко-, средне- и долгосрочной перспективе, оценка ЛНКБ КСО с } \\
\text { позиций конкурентного преимущества и возможностей использования в составе } \\
\text { компонентов маркетингово-конкурентной позиции }\end{array}$ \\
\hline $\begin{array}{l}\text { 3. Внедрение ЛНПБ КСО в } \\
\text { образовательную и } \\
\text { маркетинговую } \\
\text { деятельность вуза }\end{array}$ & $\rightarrow$ & $\begin{array}{l}\text { 3.1. Опубликование ЛНКБ КСО в аналоговых и цифровых каналах маркетинговых } \\
\text { коммуникаций вуза. 3.2. Ознакомление персонала вуза с ЛНКБ КСО, сдача экзамена и } \\
\text { получение диплома ДПО (удостоверения о повышении квалификации). } 3.3 . \\
\text { Ежегодное ознакомление персонала вуза с изменениями в ЛНКБ КСО, а также } \\
\text { практикой ее применения в деятельности образовательной организации, } \\
\text { отраслевыми и межотраслевыми практиками. 3.4. Организация внутреннего } \\
\text { конкурса непрерывного типа по сбору предложений, позволяющих } \\
\text { усовершенствовать ЛНКБ КСО вуза среди персонала и обучаемых. 3.5. Ежегодное } \\
\text { ознакомление обучаемых (членов их семей) с изменениями в ЛНКБ КСО, а также } \\
\text { практикой ее применения в деятельности образовательной организации, } \\
\text { отраслевыми и межотраслевыми практиками }\end{array}$ \\
\hline $\begin{array}{l}\text { 4. Использование ЛНПБ КСО } \\
\text { в образовательной и } \\
\text { маркетинговой } \\
\text { деятельности вуза }\end{array}$ & $\rightarrow$ & $\begin{array}{l}\text { 4.1. Изучение значимости восприятия КСО вуза как фактора и мотива } \\
\text { потребительского поведения абитуриентов, обучаемых, выпускников и членов их } \\
\text { семей на целевых региональных и национальном рынке. 4.2. Изучение значимости } \\
\text { восприятия КСО вуза как фактора и мотива потребительского поведения } \\
\text { абитуриентов, обучаемых, выпускников и членов их семей в сети филиалов } \\
\text { образовательных организаций. 4.3. Изучение значимости восприятия КСО вуза в } \\
\text { маркетинговой деятельности субъектов систем маркетинга региональных и } \\
\text { национального образовательного рынка. 4.4. Текущая ситуационная маркетинговая } \\
\text { активность по популяризации и продвижению основных положений и практики } \\
\text { применения ЛнПБ КСО. 4.5. Реализация мероприятий по оценке уровня реализации } \\
\text { лНПБ КСО вуза после окончания учебных циклов (семестр, год, цикл обучения) }\end{array}$ \\
\hline $\begin{array}{l}\text { 5. Разработка и публикация } \\
\text { отчетности вуза по } \\
\text { реализации КСО }\end{array}$ & $\rightarrow$ & $\begin{array}{l}\text { 5.1. Разработка / актуализация формы отчетности по реализации КСО и ее } \\
\text { закрепление в ЛНПБ КСО. 5.2. Публикация и маркетинговое продвижение факта } \\
\text { публик отчетности по реализации КСО вуза }\end{array}$ \\
\hline
\end{tabular}

Рисунок 1. Локальная нормативно-правовая база реализации КСО: маркетинговые аспекты формирования, использования и модернизации (внесено автором) 
ность проектных, внедренческих, эксплуатационных и инновационных процедур за счет использования внешнего информационного (в том числе отраслевого) поля, реализации бенчмаркинговых практик и разработки маркетингового и операционного прогноза внедрения, коммуникационной поддержки и продвижения ЛНПБ КСО в качестве системы информационных поводов, фиксации обратной связи по знанию / владению / использованию ЛНПБ КСО субъектами внешней и внутренней маркетинговых сред вуза, разработки и продвижения отчетности по использованию ЛНПБ КСО как мотива привлечения стейкхолдеров и субъектов систем маркетинга образовательных рынков.

Указанные инструменты адаптированы к специфике и содержанию корпоративной социальной ответственности, и при системном применении конкретным специалистом или подразделением способны обеспечить высокую информационную и коммуникационную эффективность процессов маркетингового продвижения. В то же время существенной особенностью рассматриваемого инструментария и значимым ограничением является необходимость стратегической, долгосрочной социальноэтичной ориентации образовательной организации и связанная с этим последовательная, необратимая и системная трансформация социально-этичных принципов и приоритетов в организации операционной и маркетинговой деятельности.

Следует подчеркнуть, что в настоящее время только Высшая школа менеджмента СПбГу обладает локальной нормативно-правовой базой по реализации КСО высокого качества, причем этот пример фактически является аномалией, хотя весьма содержателен и подходит для исследования, бенчмаркинга и масштабирования.

Авторский подход к характеристике содержания социально-этического компонента стратегической маркетинговой деятельности вуза представлен на рис. 2. Модель стратегического маркетинга, предложенная Ж.-Ж. Ламбеном и являющаяся образцом для организации стратегической маркетинговой активности в образовательных организациях дополнена нами в части конкретных социально-этичных атрибутов, сопровождающих процесс выработки подхода к реализации социально-этичной миссии образовательной организации и соответствующей ориентации на образовательный рынок, модернизации мультиатрибутивной модели образова- тельного продукта, соотнесения ее с актуальной маркетинговой сегментацией перспективных и целевых рынков, а также приведения в соответствие внутренней маркетинговой структуры (службы) и модернизации комплекса маркетинга (тактической маркетинговой активности).

Основой социально-этичной маркетинговой стратегии мы полагаем необходимость последовательной реализации потребностей целевых рынков в образовательных услугах и продуктах с обязательным учетом и неуклонным следованием социально-этичным нормам, правилам и ограничениям, актуальным для организационного маркетингового и образовательного процесса. Стратегическим маркетинговым решением для вуза с учетом отмеченных ограничений является образовательный продукт, характеризуемый наличием социально этичного компонента и обеспечивающий возможность системного удовлетворения нужд, потребностей и запросов потребительской триады (личность, общество, государство) как специфического субъекта спроса на образовательных рынках.

Этапами стратегического маркетингового процесса в его социально-этичной ориентации становятся модернизация состава, структуры и значимости атрибутов ценностного предложения, а также применение качественно иных критериев сегментации, направленных на определение актуальной значимости социальноэтического потребительского запроса и его особенностей (текущего уровня и перспектив управляемого формирования).

При этом мы считаем необходимым и безальтернативным модернизацию организационной структуры службы маркетинга и выделение соответствующего подразделения/специалиста, сфокусированного на корпоративной социальной ответственности вуза и ее продвижении, как в качестве самостоятельного направления маркетингово-коммуникационной активности, так и в составе элементов комплекса маркетинга, учитывающих специфику вида экономической деятельности.

Сценарий реорганизации службы маркетинга вуза, обеспечивающий возможность реализации и полноформатного маркетингового сопровождения процессов корпоративной социальной ответственности образовательной организации, представлен в табл. 1.

В сравнении с наиболее прогрессивной на данный момент времени концепцией маркетингового управления вузом, внесенной И.А.Шума- 


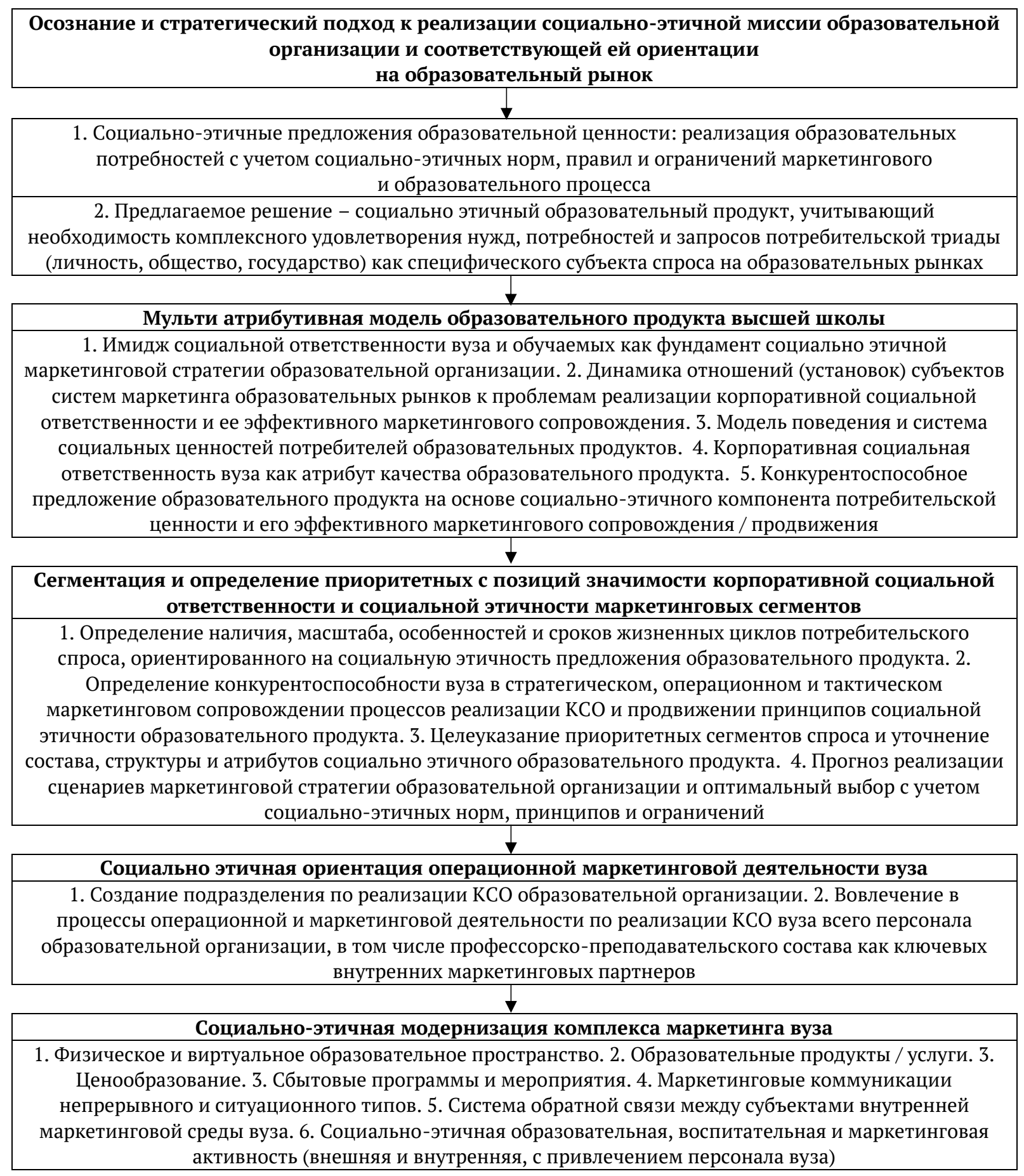

Рисунок 2. Социально-этический компонент стратегической маркетинговой деятельности вуза (на основе визуализации процесса стратегического маркетинга Ж.-Ж. Ламбена [7], дополнено автором) 
Таблица 1. Субъекты организации маркетинговой деятельности вуза с учетом социально-этичных приоритетов (на основе подхода И.А. Шумаковой [11])

\begin{tabular}{|c|c|c|}
\hline \multirow{2}{*}{$\begin{array}{c}\text { Субъекты, участвующие в } \\
\text { организации маркетинговой } \\
\text { деятельности образовательной } \\
\text { организации }\end{array}$} & \multicolumn{2}{|c|}{$\begin{array}{c}\text { Концепции организации маркетинговой деятельности образовательной } \\
\text { организации }\end{array}$} \\
\hline & $\begin{array}{c}\text { Маркетинговое } \\
\text { управление (И.А. Шумакова [11]) }\end{array}$ & $\begin{array}{c}\text { Концепция социально-этичного } \\
\text { маркетинга } \\
\end{array}$ \\
\hline $\begin{array}{l}\text { Центральное подразделение } \\
\text { маркетинга вуза }\end{array}$ & & \\
\hline $\begin{array}{l}\text { Децентрализованные } \\
\text { маркетинговые подразделения } \\
\text { фронтальных образовательных } \\
\text { единиц / дивизиональные } \\
\text { менеджеры по маркетингу }\end{array}$ & & \\
\hline $\begin{array}{l}\text { Профессорско-преподавательский } \\
\text { состав вуза }\end{array}$ & & \\
\hline $\begin{array}{l}\text { Самостоятельное подразделение / } \\
\text { специалист по КСО вуза в составе } \\
\text { центрального подразделения } \\
\text { маркетинга }\end{array}$ & & \\
\hline $\begin{array}{l}\text { Руководители подразделений и вуза } \\
\text { в целом }\end{array}$ & & \\
\hline Обучаемые & & \\
\hline Выпускники & & \\
\hline $\begin{array}{l}\text { Субъекты системы маркетинга } \\
\text { образовательных рынков }\end{array}$ & & \\
\hline
\end{tabular}

ковой, организационная поддержка реализации концепции социально-этичного маркетинга в образовательной организации подразумевает создание самостоятельного подразделения по КСО, способного реализовать организационные и маркетинговые функции, а также привлечение к ее внедрению линейных и функциональных руководителей, обучаемых и выпускников, а также максимального круга субъектов систем региональных образовательных рынков. Отметим, что итогом подобной реализации маркетинговой функции вуза должен стать широкий фундамент взаимодействий и взаимоотношений рациональной природы, учитывающий как мотивы маркетингового поведения субъектов региональных рынков, так и необходимость сегрегации социально не этичных импульсов и активностей с последующим применением соответствующего корректирующего инструментария и его маркетингового сопровождения.

Тотальное вовлечение персонала вуза, представителей функциональных и линейных подразделений, непосредственных клиентов, максимального круга маркетинговых субъектов и непрерывная, долгосрочная реализация социально-этичных маркетинговых усилий требуют использования всего спектра возможностей комплекса маркетинга образовательной организации (табл. 2).
Решение конкретных тактических задач по реализации социально-этичной маркетинговой концепции на примере конкретного образовательного учреждения характеризуется высокой сложностью, многоаспектностью, мультсубьектностью, необходимостью сочетания различных элементов комплекса маркетинга и потребностью в их непрерывном и гармонизированном взаимодействии.

Реализация прямых и обратных (на основе функциональной системы обратной связи, доступной к реализации в цифровом формате) связей между всеми субъектами внутренней маркетинговой среды и перспектива привлечения внешних субъектов позволят повысить не только объемы тактической маркетинговой активности, но и релевантно оценить уровень ее эффективности по динамике открытых для изучения клиентских групп, причем как в маркетинговом, так и в экономическом и финансовом аспектах, с возможностью расчета, оценки и интерпретации показателей маркетинговой и экономической эффективности.

Отметим также, что реализация самой, на данный момент времени, совершенной маркетинговой концепции не возможна без использования всего маркетингового потенциала персонала, который в этом случае реально становится ключевым внутренним партнером, непосред- 


\section{Таблица 2. Социально-этичные особенности реализации комплекса маркетинга образовательного учреждения. Персонал как ключевой внутренний маркетинговый партнер вуза в части маркетингового сопровождения процессов реализации КСО}

\begin{tabular}{|c|c|c|}
\hline $\begin{array}{c}\text { Элемент комплекса мар- } \\
\text { кетинга образователь- } \\
\text { ной организации }\end{array}$ & $\begin{array}{l}\text { Субъекты, участвующие в реализации } \\
\text { элемента комплекса маркетинга вуза }\end{array}$ & $\begin{array}{c}\text { Задачи реализации элемента комплекса } \\
\text { маркетинга вуза }\end{array}$ \\
\hline 1 & 2 & 3 \\
\hline $\begin{array}{l}\text { Физическое образова- } \\
\text { тельное пространство }\end{array}$ & $\begin{array}{l}\text { Модераторы физического образова- } \\
\text { тельного пространства, дивизиональ- } \\
\text { ные менеджеры по маркетингу, ППС, } \\
\text { обучаемые }\end{array}$ & \multirow{2}{*}{$\begin{array}{l}\text { Информирование абитуриентов, обуча- } \\
\text { емых и выпускников о текущих и пер- } \\
\text { спективных возможностях получения } \\
\text { образования и партнерских программах } \\
\text { с участием вуза (практики, трудоустрой- } \\
\text { ство, следующий уровень обучения, } \\
\text { преподавательская и научная деятель- } \\
\text { ность, другое) }\end{array}$} \\
\hline $\begin{array}{l}\text { Виртуальное образова- } \\
\text { тельное пространство }\end{array}$ & $\begin{array}{l}\text { Модераторы физического образова- } \\
\text { тельного пространства, центральное } \\
\text { подразделение маркетинга, дивизи- } \\
\text { ональные менеджеры по маркетингу, } \\
\text { ППС, обучаемые }\end{array}$ & \\
\hline $\begin{array}{l}\text { Ассортимент образова- } \\
\text { тельных услуг и продук- } \\
\text { тов }\end{array}$ & \multirow[t]{2}{*}{$\begin{array}{l}\text { Центральное подразделение марке- } \\
\text { тинга, дивизиональные менеджеры по } \\
\text { маркетингу, ППС, обучаемые }\end{array}$} & \multirow{2}{*}{$\begin{array}{l}\text { Изучение спроса и корректировка } \\
\text { стратегических параметров ценност- } \\
\text { ного предложения образовательных } \\
\text { услуг и продуктов на всем протяжении } \\
\text { образовательного цикла и программ } \\
\text { лояльности }\end{array}$} \\
\hline $\begin{array}{l}\text { Ценообразование на } \\
\text { образовательные услуги/ } \\
\text { продукты }\end{array}$ & & \\
\hline $\begin{array}{l}\text { Сбытовые программы и } \\
\text { мероприятия }\end{array}$ & \multirow{2}{*}{$\begin{array}{l}\text { Дивизиональные менеджеры по марке- } \\
\text { тингу, ППС, руководители, обучаемые, } \\
\text { выпускники }\end{array}$} & \multirow{2}{*}{$\begin{array}{l}\text { Продвижение и продажи образователь- } \\
\text { ных продуктов и услуг во внутренней и } \\
\text { внешней среде маркетинга образова- } \\
\text { тельной организации }\end{array}$} \\
\hline $\begin{array}{l}\text { Маркетинговые комму- } \\
\text { никации непрерывного } \\
\text { и ситуационного типов }\end{array}$ & & \\
\hline $\begin{array}{l}\text { Система обратной связи } \\
\text { между субъектами вну- } \\
\text { тренней маркетинговой } \\
\text { среды вуза }\end{array}$ & $\begin{array}{l}\text { Руководители, ППС, обучаемые, вы- } \\
\text { пускники, центральное подразделение } \\
\text { маркетинга }\end{array}$ & $\begin{array}{l}\text { Оценка ожидаемого и воспринимаемо- } \\
\text { го качества образовательных продуктов, } \\
\text { мониторинг социально-этичных про- } \\
\text { блем в операционной и маркетинговой } \\
\text { деятельности, ситуационные корректи- } \\
\text { ровки социально-этичных конфликтов } \\
\text { и проблемных ситуаций }\end{array}$ \\
\hline $\begin{array}{l}\text { Внешняя социально- } \\
\text { этичная образователь- } \\
\text { ная, воспитательная и } \\
\text { маркетинговая актив- } \\
\text { ность вуза }\end{array}$ & $\begin{array}{l}\text { Центральное подразделение маркетин- } \\
\text { га вуза, децентрализованные марке- } \\
\text { тинговые подразделения фронтальных } \\
\text { образовательных единиц / дивизио- } \\
\text { нальные менеджеры по маркетингу, } \\
\text { профессорско-преподавательский со- } \\
\text { став вуза, самостоятельное подразделе- } \\
\text { ние / специалист по КсО вуза в составе } \\
\text { центрального подразделения марке- } \\
\text { тинга, руководители подразделений и } \\
\text { вуза в целом, обучаемые, выпускники, } \\
\text { субъекты системы маркетинга образо- } \\
\text { вательных рынков }\end{array}$ & \multirow{2}{*}{$\begin{array}{l}\text { Реализация корпоративной социальной } \\
\text { ответственности вуза в составе обра- } \\
\text { зовательного продукта. Продвижение } \\
\text { КСО вуза как компонента потребитель- } \\
\text { ской ценности и конкурентного пре- } \\
\text { имущества вуза. Создание и развитие } \\
\text { потребительских сообществ, разделя- } \\
\text { ющих социально-этичные ценности и } \\
\text { приоритеты. Разработка и реализация } \\
\text { программ лояльности, учитываю- } \\
\text { щих социально-этичные особенности } \\
\text { образовательных продуктов вуза и } \\
\text { их маркетингового сопровождения. } \\
\text { Формирование и развитие социально- } \\
\text { этичной и ответственной репутации } \\
\text { как нематериального маркетингового } \\
\text { актива образовательной организации }\end{array}$} \\
\hline $\begin{array}{l}\text { Внутренняя социально- } \\
\text { этичная образователь- } \\
\text { ная, воспитательная и } \\
\text { маркетинговая актив- } \\
\text { ность вуза }\end{array}$ & $\begin{array}{l}\text { Персонал вуза: руководители } \\
\text { подразделений, профессорско- } \\
\text { преподавательский состав, обучаемые }\end{array}$ & \\
\hline
\end{tabular}


ственно вовлеченным в тактические (а при необходимости и возможности - в операционные и стратегические) маркетинговые инициативы.

Считаем важным подчеркнуть необходимость прямого соотнесения целевых социальноэтичных показателей результативности персонала вуза с уровнем материальной и нематериальной мотивации (что фактически не наблюдается в существующей системе, где соблюдение социально-этических норм представителями ППС и руководства в значительной степени стимулируется нематериально или на основе малобюджетных методов и технологий).

Кроме того, все социально-этичные операционные, маркетинговые и иные функциональные усилия вуза не достигнут эффективности, если представители ППС личным примером, общением и отношением к служебной и учебной дисциплине будут демонстрировать обучаемым абстрактность и недостижимость идеальных социально-этичных приоритетов в реальной образовательной деятельности и процессах жизнедеятельности.

Подводя итог сказанному, подчеркнем наличие обоснованных инструментов и методов социально-этичной маркетинговой деятельности образовательной организации, обеспечивающих решение конкретных внешних и внутрен- них проблем в маркетинговых взаимодействиях и образовательном процессе, но требующих системной модернизации локальной нормативноправовой базы реализации корпоративной социальной ответственности (ЛНПБ КСО), содержания социально-этического компонента стратегической маркетинговой деятельности вуза; тотального вовлечения персонала в реализацию социально-этичных приоритетов, а также соответствующей модернизации маркетинга образовательных учреждений.

Эффективность полноформатного маркетингового сопровождения процессов формирования, реализации и оценивания корпоративной социальной ответственности на образовательных рынках зависит от степени системности вырабатываемых маркетинговых решений, уровня их согласованности и непрерывности и длительности срока прикладного внедрения. Указанные обстоятельства и формируют репутацию образовательной организации, позволяя использовать социально-этичное преимущество как резерв конкурентоспособности, основу формирования долгосрочной потребительской лояльности, а на ее базе - запас конкурентной и операционной устойчивости вуза на современных высоко конкурентных образовательных рынках.

\section{Библиографический список}

1. Агибалова В.Г., Гужвина А. С. Цифровые технологии в управлении персоналом в сфере государственного и муниципального управления // Заметки ученого. 2020. № 10. С. 127-129.

2. Агибалова В.Г., Дорошенко М. А. Эффективность современного обучения персонала с использованием цифровых технологий в сфере государственного и муниципального управления // Заметки ученого. 2020. № 10. С. $130-132$.

3. Агибалова В.Г., Зиннер А. С. Методика управления проектом в государственном и муниципальном управлении // Заметки ученого. 2020. № 10. С. 123-126.

4. Доклад о социальных инвестициях в России. URL: https://amr.ru/projects/1111/

5. Кашкина М.Г. Медиакультура и ее место в контексте философского знания // Культурная жизнь Юга России. 2011. № 1 (39). С. 109.

6. Кашкина М.Г. Медиакультура информационного общества в аспекте философского дискурса. Диссертация на соискание ученой степени кандидата философских наук / Краснодарский государственный университет культуры и искусств. Краснодар, 2012.

7. Ламбен Ж.-Ж. Стратегический маркетинг. Европейская перспектива. СПб., Наука, 1996. -545 с.

8. Напалкова М.Г., Сигида Д. А. Медиакультура как вызов постмодернистскому и информационному обществу // В сборнике: Сборник научных статей профессорско-преподавательского состава и студентов Российских научно-образовательных учреждений. Берлин, 2020. С. 272-276.

9. Национальный стандарт Российской Федерации ГОСТ Р ИСО 26000-2012 «Руководство по социальной ответственности» URL: https://docs.cntd.ru/document/1200097847

10. Третьяк О.А. Корпоративная социальная ответственность российских компаний // Российский журнал менеджмента. 2015. № 2. URL: https://www.marketing.spb.ru/mr/business/Corporate_Governance.htm

11. Шумакова И.А. Управление маркетинговой деятельностью российских вузов в условиях развития национальных и глобальных образовательных рынков. Дис. ... д-ра экон. наук. Белгород, НИУ БелГУ, 2021. С. $210-211$ 